\title{
Early detection of interstitial lung disease in asbestos exposed non-smoking workers by mid-expiratory flow rate and high resolution computed tomography
}

\author{
Željko Dujić, Jadranka Tocilj, Marko Sarić
}

\begin{abstract}
Ten years of lung function and radiological findings in six non-smoking asbestos exposed subjects who had increased mid-expiratory flow rate $\left(\mathrm{FEF}_{25-75 \%}\right)$ as the only functional abnormality were prospectively analysed. A biphasic change in $\mathbf{F E F}_{25-75 \%}$ was noted. It initially increased up to the fifth year, and then a decrease was seen. In the final three years of the study, FEF $_{25-75 \%}$ reduction correlated well with a decrease in pulmonary capacity for $\mathrm{CO}$ (DLCO). During that time high resolution computed tomography (HRCT) probability scores correlated inversely with FEF $_{25-75 \%}$ and with DLCO, whereas chest radiography was unchanged (International Labour Organisation (ILO) profusion below 1/1). For five of the six subjects HRCT probability of asbestosis was intermediate. An increase in $\mathbf{F E F}_{25-75 \%}$ in some asbestos exposed non-smoking workers may be one of the earliest functional signs indicative of future development of parenchymal asbestosis. Early asbestos related parenchymal abnormalities are seen more frequently on HRCT than on chest radiography.
\end{abstract}

Long term exposure to asbestos dust can result in interstitial fibrosis of the pulmonary parenchyma. Early diagnosis of asbestosis is difficult because standard pulmonary function tests are insensitive in detection of mild or early disease and because symptoms and physical findings are present only in

Department of Physiology, Zagreb University School of Medicine in Split, IL Ribara 4, 58000 Split, Yugoslavia

Ž Dujić

Pulmonary Division, Clinical Hospital "Firule," Split

J Tocilj

Institute for Medical Research and Occupational Health, University of Zagreb

M Sarić advanced asbestosis. ${ }^{1}$ Some investigators have suggested that functional abnormalities (reduction in vital and diffusing lung capacities) may precede changes in chest radiography analysed with the International Labour Organisation (ILO) classification. ${ }^{23}$ Recent studies have shown that high resolution computed tomography (HRCT) is more sensitive than chest radiography for detecting diffuse parenchymal abnormalities in asbestos exposed subjects. ${ }^{45}$

A decrement in mid expiratory flow rate $\left(\mathrm{FEF}_{25-75 \%}\right.$; a measurement of flow that represents a reflection of small airway obstruction) has been reported in nonsmoking asbestos exposed subjects. ${ }^{6}$ Recent studies of pathology in animals ${ }^{7}$ and humans ${ }^{8}$ have shown that asbestos fibres were deposited first in respiratory bronchioles, resulting in peribronchiolar fibrosis. It was suggested that an abnormal $\mathrm{FEF}_{25-75 \%}$ may indicate a population at risk for pulmonary fibrosis, or obstructive airway disease, or both. ${ }^{6}$

To investigate the possibility that abnormal $\mathrm{FEF}_{25-75 \%}$ could be the early sign of future interstitial asbestosis, we conducted a longitudinal study in which we included only asbestos exposed nonsmoking subjects with abnormal $\mathrm{FEF}_{25-75 \%}$. In six non-smoking men (median age 44, range 37-51 years, median asbestos exposure at the start of the study 13 years, range nine to 17 years) the earliest functional abnormality was an increase in $\mathrm{FEF}_{25-75 \%}$. These six subjects were chosen from a cohort of 285 workers in an asbestos cement factory. They were exposed predominantly to chrysotile asbestos. Spirometric parameters (forced vital capacity (FVC), forced expiratory volume in one second $\left(\mathrm{FEV}_{1}\right), \mathrm{FEV}_{1} /$ FVC, and $\left.\mathrm{FEF}_{25-75 \%}\right)$ were measured with a dry spirometer (Vitalograph, UK). The pulmonary diffusion capacity for CO (DLCO) was measured using a single breath method (Morgan MK4, UK) yearly for 10 years. Reference values for spirometry were according to Cotes, ${ }^{9}$ and for DLCO according to Cotes and Hall. ${ }^{10}$ Annual examination included chest radiographs (graded according to the 1980 ILO classification), and in the final three years HRCT scans in prone and supine positions (Siemens 


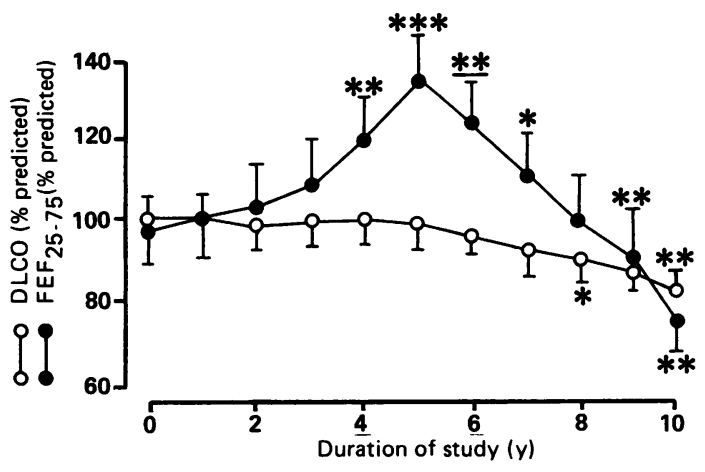

Mean ( $\pm S E M) F E F_{25-75 \%}$ and DLCO of six non smoking workers exposed to asbestos. ${ }^{\star} p<0.05$, ${ }_{\star \star \star} p<0.01(\star \star p<0.005) ;{ }^{\star \star \star} p<0.001$.

SOMATOM DRG scanner). The HRCT scans were graded as high, intermediate, and low probabilities of asbestosis on the basis of the multiplicity and extent of parenchymal morphological abnormalities. ${ }^{4}$

Data are given as mean $( \pm S E M)$ or median with range. Student's $t$ test for paired data was used for statistical analysis. For correlation analysis least square linear regression analysis was employed.

The earliest functional change was a significantly increased $\mathrm{FEF}_{25-75 \%}(121 \pm 13 v 98 \pm 11 \%$ of the predicted values; $p<0.01$ ) four years after the start of the study (figure). This increase continued during the next year with the highest value found at the fifth annual examination $(136 \pm 11 \%)$. The initial increase in $\mathrm{FEF}_{25-75 \%}$ was followed by a decrease (figure). Other spirometric parameters (FVC, $\mathrm{FEV}_{1}$, $\mathrm{FEV}_{1} / \mathrm{FVC}$ ) were unchanged during the study. The DLCO measured during the first seven years was unchanged, whereas it was significantly decreased in the final three years (from $101 \pm 4$ to $83 \pm 6 \%$ for the last measurement, $p<0.005$ ). A significant correlation was found between $\mathrm{FEF}_{25-75 \%}$ and DLCO data from the last three examinations $(r=0.88$; $\mathrm{p}<0.01)$. During the study chest radiographs gave no evidence for pleural or parenchymal fibrosis. For the last examination ILO profusion for small opacities was graded $1 / 0$ in three subjects. Five subjects had an abnormal HRCT suggestive of asbestosis, however, in the last two examinations, whereas one subject had a near normal HRCT. Among previously described characteristic HRCT features of parenchymal asbestosis ${ }^{4}$ we found subpleural curvilinear lines, thickened interstitial short lines, subpleural dependent density, and honey- combing. All five subjects had intermediate (HRCT score 3-3.5) probability of asbestosis. Significant inverse correlations were found between HRCT and $\mathrm{FEF}_{25-75 \%}$ data from the last three examinations $(\mathrm{r}=-0.71 ; \mathrm{p}<0.05)$, and between HRCT and DLCO $(r=-0.64 ; p<0.05)$. None of the usual clinical findings of asbestosis (finger clubbing and basal rales ${ }^{1}$ ) were noted in these subjects.

In the present study we found that exposure to asbestos may cause a biphasic change in $\mathrm{FEF}_{25-75 \%}$ (initial increase followed by a decrease) in nonsmoking subjects. This change may be due, in part, to peribronchiolar fibrosis; an early stage of this process could increase small airway stability resulting in displacement of the "equal pressure point" towards the mouth with reduced airway compression during forced expiration and increased airflow. The advanced stage of peribronchiolar fibrosis distorts and reduces the diameter of the small airways resulting in decreased airflow. In five out of six subjects the functional decrements in $\mathrm{FEF}_{25-75 \%}$ and $\mathrm{DCO}$ (a measurement that is considered a reflection of interstitial lung disease) were correlated with abnormal HRCT suggestive of asbestosis, whereas chest radiographs were unchanged. It appears that early diagnosis of asbestosis could be made in some asbestos exposed non-smoking subjects with normal chest radiographs by HRCT and functional $\mathrm{FEF}_{25-75 \%}$ monitoring.

1 Becklake MR. Asbestos-related diseases of the lungs and pleura: current clinical issues. Am Rev Respir Dis 1988;126:187-94.

2 Jodoin G, Gibbs GW, Macklem PT, et al. Early effects of asbestos exposure on lung function. Am Rev Respir Dis 1971;104:525-34.

3 Rosenstock L, Barnhart S, Heyer NJ, et al. The relations among pulmonary function, chest roentgenographic abnormalities, and smoking status in an asbestos-exposed cohort. $\mathrm{Am} \mathrm{Rev}$ Respir Dis 1988;138:272-7.

4 Aberle DR, Gamsu G, Ray CS, et al. Asbestos-related pleural and parenchymal fibrosis: detection with high-resolution CT. Radiology 1988;166:729-34.

5 Staples CA, Gamsu G, Ray CS, et al. High resolution computed tomography and lung function in asbestos-exposed workers with normal radiographs. Am Rev Respir Dis 1989;139: 1502-8.

6 Mohsenifar Z, Jasper AJ, Mahrer T, et al. Asbestos and airflow limitation. J Occup Med 1986;28:817-20.

7 Gross P, De Treville RTP. Experimental asbestosis. Studies on the progressiveness of the pulmonary fibrosis caused by chrysotile dust. Arch Environ Health 1967;15:638-49.

8 Churg A. Current issues in the pathologic and mineralogic diagnosis of asbestos induced disease. Chest 1983;84:275-80.

9 Cotes JE. Lung function at different stages of life, including reference values. In: Cotes JE, ed. Lung function, 3rd ed. Oxford: Blackwell Scientific Publications, 1975:340-95.

10 Cotes JE, Hall AM. The transfer factor for the lung; normal values in adults. In: Arcangeli P, ed. Normal values for respirator function in man. Torino: Panminerva Medica, 1970: $327-43$.

Accepted 4 February 199.1 